\title{
Construction and Lifting Technology for Column Subsection of Tension Leg Platform
}

\author{
Lixin Song \\ Offshore Oil Engineering (Qingdao) Co., Ltd., No. 492, Lianjiang Road, Qingdao \\ Economic-technological Development Zone, China \\ songlx@mail.cooec.com.cn
}

Keywords: tension leg platform, TLP, Column subsection, construction, lifting and assembly

Abstract. Construction and lifting technology of column subsection is the key to build the lower hull of tension leg platform (TLP). Reasonable block dividing and build process could reduce the fabrication of dock workload, control welding distortion and dimensional accuracy and shorten the construction period. Optimization of lifting point design is advantageous safeguard for fabricating. This paper expounds the fabricating procedure and subsection lifting method of column subsection of the deep water tension leg platform, for TLP's construction provide favorable support.

\section{Introduction}

Tension leg platform (TLP), as a kind of typical deep water floating platform, is widely used in the deep water oilfield due to the small heave motion ${ }^{[1-3]}$. The construction of the tension leg platform is divided into two parts: the construction of the lower hull and the construction of the upper topside. The construction process of subsection fabricating and dock closed was adopted by a large number of marine engineering equipment companies ${ }^{[4-5]}$. Reasonable block dividing, transportation, lifting technology could reduce the assembling and welding workload of the dock, shorten the construction period and control the dimensional accuracy of welding distortion. This paper expounds the fabricating procedure and subsection lifting method of column subsection of the deep water tension leg platform.

\section{Main parameters of tension leg platform}

The main contour parameters for tension leg platforms are listed in Table 1, and block division of the lower hull is shown in Fig. 1.

Table 1 The main parameters for TLP

\begin{tabular}{ll}
\hline Structure & Parameters \\
\hline Total height for hull: & $56.5 \mathrm{~m}$ \\
Column outer diameter: & $19.5 \mathrm{~m}$ \\
Column height: & $48 \mathrm{~m}$ \\
Column center distance: & $59 \mathrm{~m}$ \\
Column number: & $4 \mathrm{~m}$ \\
Pontoon height & $8.5 \mathrm{~m}$ \\
The design draft: & $30 \mathrm{~m}$ \\
The upper topside size: & $62 \mathrm{~m} * 58 \mathrm{~m}$ \\
Topside height: & $9.5 \mathrm{~m}$ \\
Total weight: & about 27000 tons \\
\hline
\end{tabular}




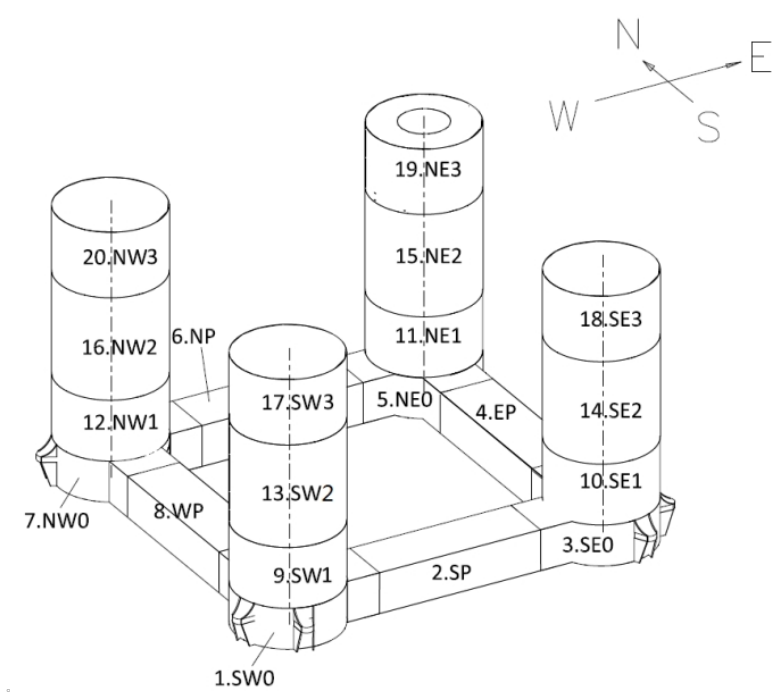

Fig. 1 Block division of the lower hull for TLP

\section{Construction method for column section of tension leg platform}

The four columns of tension leg platform (TLP) are labeled as SW, SE, NW and NE, respectively. Each column is divided into three section (SW1,SW2,SW3) and the weight of single column subsection is less than 700T (including part of outfitting weight). The total height for column is $48 \mathrm{~m}$. The docking was assembled along the direction with overlapping, and the block division of column was shown in Fig. 2. Taken column SW1 as an example, the construction process was introduced. At the same time, SW1 section is divided into four external subsections, such as SW111 SW112, SW113and SW114, and two internal subsections such as SW101, SW102.

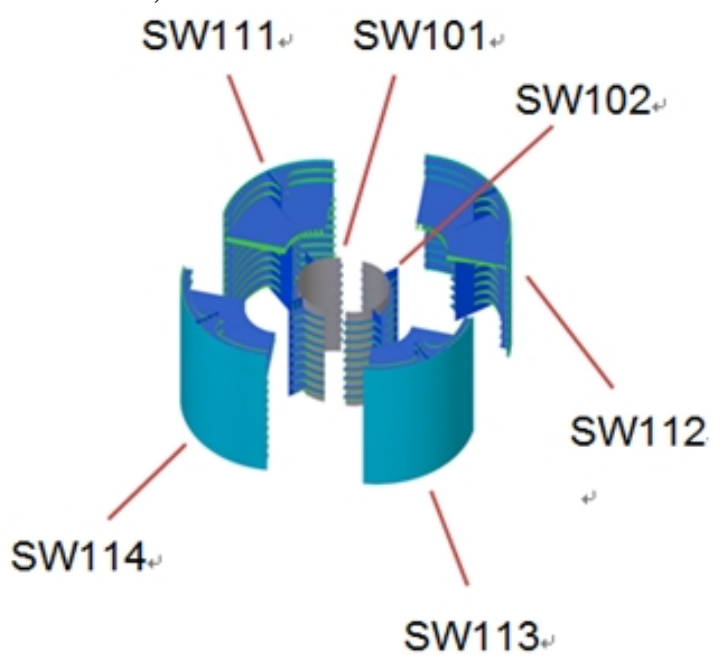

Fig. 2 Block division of column

The fabrication process of external subsections and internal subsections are shown in Fig. 3 and Fig. 4, respectively. 


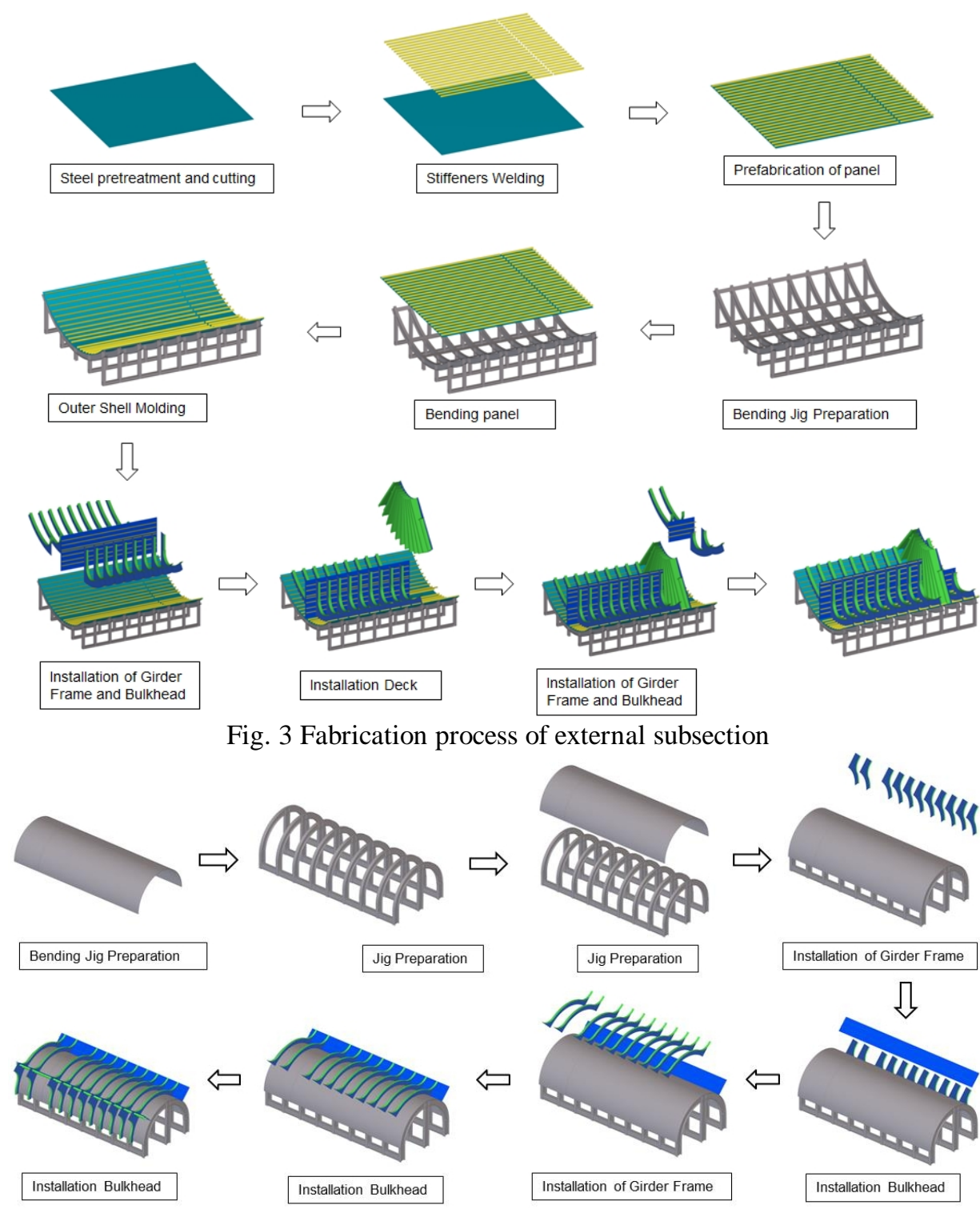

Fig. 4 Fabrication process of internal subsection

After six subsections were prefabricaed in the workshop, the subsection of SW101 was assembled with SW111 and SW114, while the subsection SW102 was assembled with SW112 and SW113. The SW1 section was included by two half-cylinder blocks, which is convenient for hoisting and transportation in the site. In addition, the half-column section was transported using SPMT. The SPMT tractor was arranged with $2 * 10$ axises and then closured. The transportation and assembly of column section was shown in Fig. 5. 

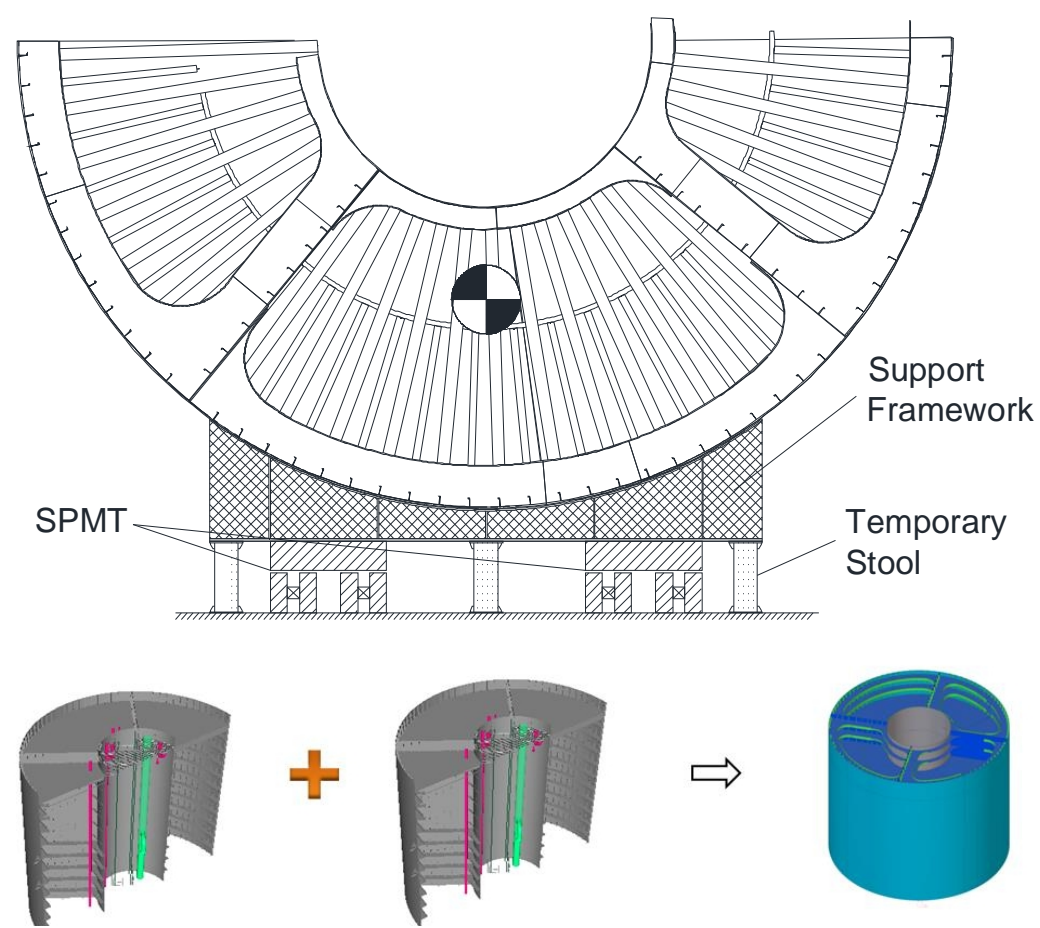

Fig. 5 Transportation and assembly of column section.

\section{Lifting method for column section of tension leg platform}

After the column segment of tension leg platform were closured in the dock, final assembly was performed by means of $800 \mathrm{~T}$ gantry crane. 24 lifting points were set up uniformly, which could effectively reduce the stress concentration. In the precast stage, the lifting point is prefabricated with column segment as a whole, which could improve the overall strength of the structure and lifting point. The lifting point could be cut off after the completion of the lifting, as shown in Fig. 6.

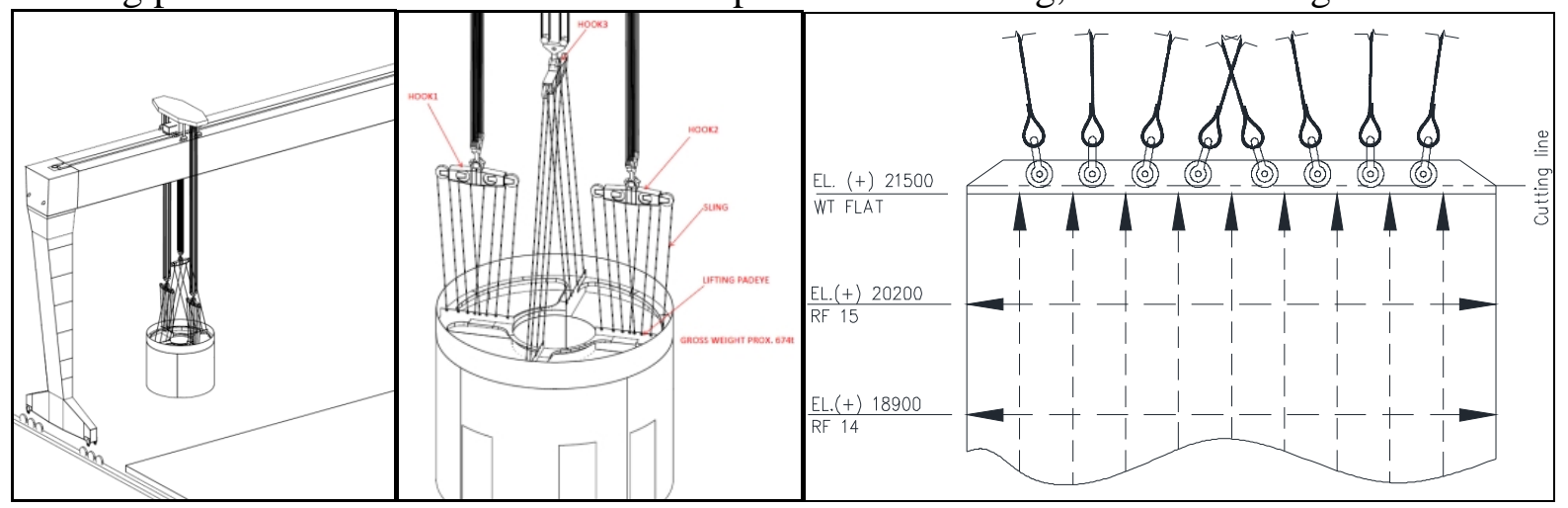

Fig. 6 Lifting and lifting point layout

Lifting analysis was performed by measns of Ansys software, and shell 63 element was used for segmented plate, beam188 element was used for beam and profile, and link10 element for sling.

The material properties:

Modulus of elasticity: $201 * 10^{3} \mathrm{~N} / \mathrm{mm}^{2}$

Poisson's ratio: 0.3

Density: $7.85 * 10^{-6} \mathrm{~kg} / \mathrm{mm}^{3}$

Yield strength: $\mathrm{FY}=355 \mathrm{~N} / \mathrm{mm}^{2}$

The boundary conditions: The nodes at the bottom of SW1 subsection are constrained, where $\mathrm{X}=0$ and $\mathrm{Y}=0$. The nodes at the top of sling are constrained. 


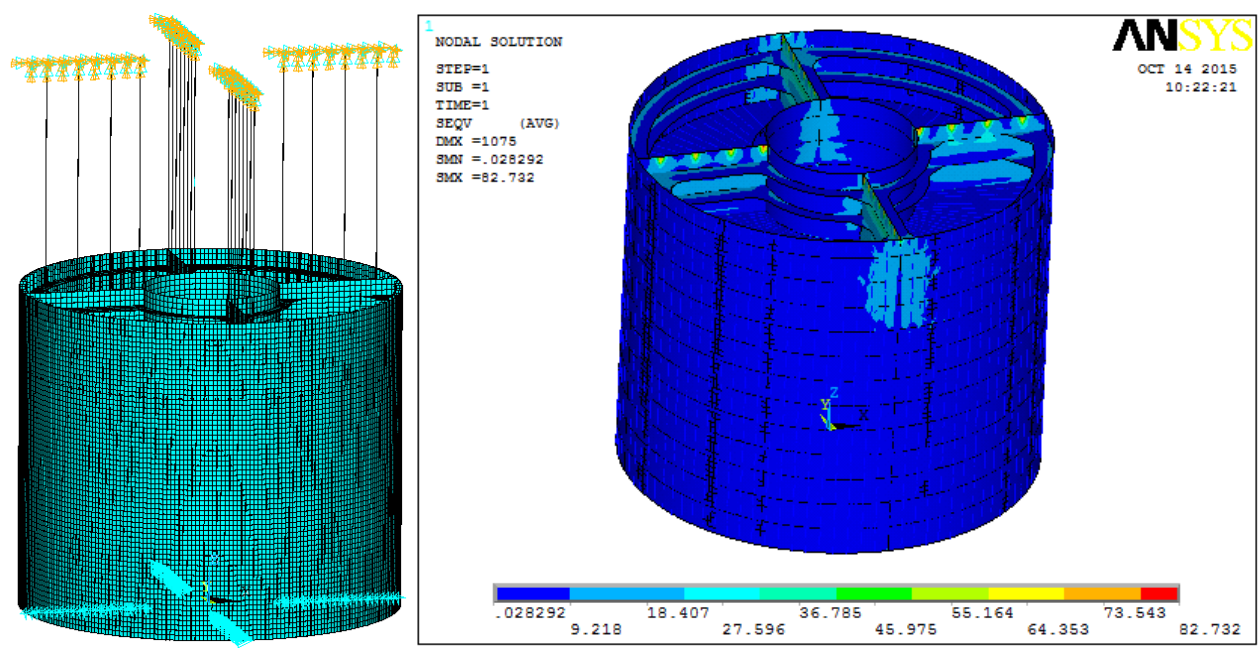

Fig. 7 Ansys model and computing clouds for column section of TLP

According to the results of the calculation in Fig. 7, the maximum stress of lifting SW1 is 82.73Mpa, and the counterforce of each node along the sling is 29.13T. Therefore, suspension centre with $35 \mathrm{~T}$ or above could be chosen. The stress of the structure distributes uniform with less stress concentration, and the lifting design could meet the requirement of structure strength. The lifting work table of SW1 are shown in table 2.

Table 2 Lifting work table of SW1

\begin{tabular}{|c|c|c|c|c|}
\hline \multirow{2}{*}{ Crane } & \multicolumn{4}{|c|}{ 800T gantry crane } \\
\hline & Hook & Hook I (EAST) & Hook II（WEST） & Hook III \\
\hline \multirow{4}{*}{ parameter } & Spacing $/ \mathrm{m}$ & \multicolumn{3}{|c|}{14} \\
\hline & Center distance $/ \mathrm{m}$ & 7 & 7 & 7 \\
\hline & Lifting weight / T & 400 & 400 & 400 \\
\hline & Total lifting weight / T & \multicolumn{3}{|c|}{800} \\
\hline \multirow{5}{*}{$\begin{array}{l}\text { Lifting } \\
\text { weight }\end{array}$} & Structure weight / T & 231 & 231 & 232 \\
\hline & Sling weight / T & 3.2 & 3.2 & 3.5 \\
\hline & Shackle weight / T & 0.17 & 0.17 & 0.17 \\
\hline & $\begin{array}{l}\text { The dynamic } \\
\text { magnification coefficient }\end{array}$ & 1.05 & 1.05 & 1.05 \\
\hline & Total lifting weight / $\mathrm{T}$ & 246.1 & 246.1 & 247.5 \\
\hline \multirow{2}{*}{$\begin{array}{l}\text { Utilization } \\
\text { rate }\end{array}$} & Maximum load utilization & $61.5 \%$ & $61.5 \%$ & $61.9 \%$ \\
\hline & total utilization rate & \multicolumn{3}{|c|}{$92.5 \%$} \\
\hline \multirow[b]{2}{*}{ rigging } & Shackle & shackle 35T-eight & shackle 35T-eight & shackle 35T-eight \\
\hline & Sling & $\begin{array}{c}\text { The minimum } \\
\text { breaking force: } \\
2900 \mathrm{Kn} \text {; } \\
\text { Minimum diameter: } \\
85 \mathrm{~mm}\end{array}$ & $\begin{array}{c}\text { The minimum } \\
\text { breaking force: } \\
2900 \mathrm{Kn} ; \\
\text { Minimum diameter: } \\
85 \mathrm{~mm}\end{array}$ & $\begin{array}{c}\text { The minimum } \\
\text { breaking force: } \\
2900 \mathrm{Kn} \text {; } \\
\text { Minimum } \\
\text { diameter: } 85 \mathrm{~mm}\end{array}$ \\
\hline
\end{tabular}

\section{Conclusions}

Reasonable block division is a key factor of column section construction for TLP. In this process, both the equipment capacity of building ground and workshop and the structure strength of transportation and hoisting should be considered. Multi-point and optimized design of lifting point could effectively reduce the stress concentration, which is benefit for the the lifting of column section for TLP.

\section{References}

[1] Yang Chunhui, Dong Yanqiu, The Developing History and Trend of Tension Leg Platform, J. China Offshore Platform, 12 (1997) 255-258.

[2] Bao Yingbin, Shu Zhi, Li Runpei, A study on mini-tension leg platform types in medium water, J. OCEAN ENGINEERING, 19 (2001) 7-12. 
[3] Li Runpei, Xie Yonghe, Shu Zhi, A Review on the Technical Development of Deep Water Offshore Platform, J. China Offshore Platform, 18 (2003) 1-5.

[4] The Group for Typical Deep Water Platform Conceptual Design Fabrication and Installation for TLP, J. Shipbuilding of china, 46 (2005) 457-463.

[5] Hein N W, Wall C J, Young C D, Welding and Fabrication for the Jolliet Project, C. OTC, 6361 (1990) 159-166. 